\title{
Effective Property Rights, Conflict and Growth
}

\author{
Francisco M. González *
}

First version: January 2002

This version: February 2003

\begin{abstract}
This paper develops a theory of the interaction between appropriative conflict and economic growth. Appropriative conflict, as measured by the diversion of resources, is viewed as the cost of securing effective property rights. We identify conditions under which conflict rises or falls as the rate of economic growth improves. The main implication of the analysis is that if the quality of property rights is sufficiently poor then faster economic growth stimulates the allocation of resources to appropriative activities and might result in decreased social welfare.
\end{abstract}

Key Words: property rights, appropriative conflict, security of property, investment, growth. JEL classification: D23, O10, O40

${ }^{*}$ Department of Economics, University of British Columbia, 926-1873 East Mall, Vancouver, BC V6T 1Z1, Canada. E-mail address: gonzalez@econ.ubc.ca. I thank Mick Devereux, Mukesh Eswaran, Herschel Grossman, Stergios Skaperdas and especially Hugh Neary for helpful comments and discussions. 


\section{Introduction}

The efforts of men are utilized in two different ways: they are directed to the production or transformation of economic goods, or else to the appropriation of goods produced by others. ${ }^{1}$

\section{Vilfredo Pareto}

Empirical growth studies increasingly emphasize the relationship between sociopolitical conflict and poor property rights, poor economic policies and, ultimately, poor economic performance. Conversely, political scientists emphasize the economic roots of sociopolitical conflict. For instance, in their study of minorities at risk, Gurr (1993, page 286) and his associates conclude that "politicized communal contention over economic distribution issues is the prevalent form of politically relevant ethnicity in Africa". Scholars recognize that issues of reverse causality and endogeneity are likely to be important in this context and, accordingly, the need for theoretical analyses of the relationship between the security of property, conflict and growth. ${ }^{2}$

Motivated by the large variations in long-run economic performance and sociopolitical conflict across countries and within countries over time, this paper develops a theory of appropriative conflict, one that emphasizes the quality of property rights and economic growth. Conflict is simply viewed as a situation in which private parties spend resources in an attempt to defend their claims to property and challenge those of others. Among the issues to be considered are: Is the intensity of conflict likely to rise or to decline with economic growth? To what extent does conflict harm economic growth and social welfare? More generally, what governs the relationship between the security of property, conflict and economic performance?

These questions are addressed in the context of an economy in which institutions that protect the output of individual producers are less than perfect. Accordingly, individual production is subject to appropriation by others. A central premise is that the value of high quality institutions that enforce property and contractual rights lies not only in that they promote investment, but

\footnotetext{
${ }^{1}$ As quoted by Hirshleifer (1988).

${ }^{2}$ For evidence from cross-country studies, see Barro (1991), Easterly and Levine (1997), Keefer and Knack (1997) and Hall and Jones (1999). Related case studies include De Soto (1989), Homer-Dixon (1994), Besley (1995) and André and Platteau (1998).
} 
also in that they suppress the diversion of resources towards appropriative activities. Otherwise, private agents lobby the government to influence fiscal transfers, or they resort to litigation to take advantage of ambiguities in property rights, resources are required to bribe corrupt government officials, or they are needed to pay for protection. We use the proportion of aggregate resources that are allocated into appropriative activities as a measure of the intensity of conflict. We view conflict as the cost of securing effective property rights.

The analytical framework is that of a Neoclassical growth model with a linear production technology, to which we incorporate a technology of conflict, which takes otherwise productive resources as an input and it summarizes the process of appropriative competition among agents. This approach to modeling appropriative competition is fairly standard and simple and has been usefully applied in several contexts. ${ }^{3}$ Our approach differs from much of the recent literature, which considers the problem of conflict by appropriation from a common pool, in that we explicitly account for the distinction between the defense and the challenge of individual claims to property. In this context, the security of property becomes the output of the technology of conflict. In effect the technology of conflict determines the cost of establishing effective property rights, given the exogenous quality of the underlying property rights system. ${ }^{4}$

We identify conditions under which conflict rises or falls as the rate of economic growth improves. The underlying mechanism can be understood by considering the influence of an improvement in the quality of property rights. Relatively higher quality property rights are associated with more secure property, which raises the opportunity cost of appropriative activities and, thus, encourages the allocation of resources into productive investment. This has two effects. First, it reduces the diversion of resources and, thus, the intensity of conflict. Second, it promotes growth. However, growth that is not accompanied by sufficiently secure property encourages appropriative competition and, thus, induces more intense conflict. We find that the

\footnotetext{
${ }^{3}$ An enormous literature models tournaments, conflict and rent-seeking as contests, in which individuals compete for a prize by spending resources in order to appropriate part or all of the prize. See Tullock (1967), Krueger (1974), Bhagwati (1982), Hirshleifer (1988, 1991a, 1991b), Skaperdas (1992, 1996), Esteban and Ray (1999) and Grossman (2001).

${ }^{4}$ Hirshleifer (1988, 1995), Skaperdas (1992), Grossman and Kim (1995), Neary (1997), Lee and Skaperdas (1998), Esteban and Ray (1999) and Grossman and Mendoza (2002) develop equilibrium models of appropriative conflict. They all abstract from economic growth.
} 
net effect of growth on conflict depends critically on the quality of property rights.

The relevance of institutional quality for the diversion of resources is highlighted in recent discussions of institutional change in Sub-Saharan Africa and the East European transition to capitalism. For instance, André and Platteau (1998) suggest that rising land disputes were closely related to the increasing individualization of land rights in Rwanda during the period 1988-1993. Shleifer (1997) links the apparent ineffectiveness of Russia's rapid economic liberalization to its slow institutional transition. In this regard, we formalize the hypothesis that substantial institutional improvement might be necessary if economic growth is to take place without exacerbating the diversion of resources. Furthermore, we identify conditions under which the social cost associated with the misallocation of resources can outweigh the social benefit associated with faster growth. Thus, the present model shows why certain institutional improvements might result in decreased welfare.

Recent work has emphasized how a negative relationship is likely to arise between appropriative activities and economic performance and how coordination problems may be important in this context. ${ }^{5}$ The present paper also seeks to understand why appropriative activities are prevalent in some economies but not in others; but we bring attention to the role of property rights in shaping the influence of growth on conflict. Specifically, the main implication of our model is that, when the quality of property rights is sufficiently poor, faster economic growth stimulates the allocation of resources to appropriative activities. This may shed light into the apparent lack of a simple relation between the extent of appropriative activities and growth performance and, in particular, the somewhat puzzling coexistence of remarkable growth and substantial corruption, political patronage and rent-seeking activities, as illustrated by the experience of economies such as Thailand and Malaysia during the 1970s and 1980s (Khan and Jomo (2000)).

The present paper is close in spirit to the work of Grossman and Kim (1996). They show how a negative relationship between the security of property and growth might arise because resources

\footnotetext{
${ }^{5}$ See, e.g., Baumol (1990), Murphy et al. (1991, 1993), Sturzenegger and Tommasi (1994) and Baland and Francois (2000).
} 
must be diverted away from productive investment in order to secure effective property rights. 6 In its emphasis on how the intensity of appropriative competition responds to the returns to productive activities, our analysis is also related in spirit to the work of Tornell and Lane (1999). They show how appropriative activities might be exacerbated by productivity increases to the extent that economic growth may be ultimately depressed. Two important dimensions where our framework differs from theirs are our focus on the quality of property rights and on the fact that securing effective property rights is a costly activity.

The following section presents the model to be analyzed. Section 3 describes the conditions that characterize an equilibrium. In Section 4, we examine the relationship between growth and the security of property. Section 5 discusses the implications of the model for the relationship between conflict and growth. In Section 6, we discuss the implications for social welfare. Section 7 concludes. Proofs of all propositions are provided in an appendix.

\section{A Model of Growth, Conflict and the Security of Property}

This section first presents the model to be analyzed and then briefly discusses how our approach is informed by recent empirical research on economic growth.

We consider a society where many individuals are distributed among $n \geq 2$ groups. At every date $t \geq 0$, agent $i$ may allocate an amount $k_{i, t+1} \geq 0$ of resources to produce $A k_{i, t+1}$ $(A>0)$ units of output that become available at date $t+1$. However, his claims over $A k_{i, t+1}$ are insecure. Instead, initial claims must be converted into effective property rights. Agent $i$ can influence this process by allocating an amount $x_{i, t+1} \geq 0$ of his resources at date $t$ into appropriative activities.

How appropriative competition influences the security of property is summarized by a technology of conflict. This approach is fairly standard and has been used in several contexts (see footnote 3 above). In contrast with most of the literature, however, we distinguish between

\footnotetext{
${ }^{6}$ In a related paper, Tornell (1997) explores the relationship between income levels and growth in the context of a model of endogenous switches between common property and private property. Also, see Benhabib and Rustichini (1996) and LLoyd-Ellis and Marceau (2002).
} 
the defense of one's own claims to property and the challenge of those of others. Specifically, we assume that the outcome of appropriative competition is such that agent $i$ appropriates the share $p_{t+1}^{i, i}$ of his next-period output and the share $p_{t+1}^{i, j}$ of agent $j$ 's next-period output. Two benefits are associated with this specification. First, it is a natural generalization of the standard specification of the conflict technology, which restricts conflict to take place by appropriation from a common pool (see footnote 8 below). Second, under this specification, the fraction of his own output that agent $i$ retains, $p_{t+1}^{i, i}$, provides a natural measure of the security of his claims to property. For simplicity, we assume that appropriative competition is symmetric and anonymous. Thus, agent $i$ 's appropriative activities at date $t$ in effect challenge the claims to next-period output by one randomly selected individual in each of the other $n-1$ groups and, symmetrically, each agent's claims are challenged by $n-1$ other agents. Specifically, we let

$$
p_{t+1}^{i, i}=\frac{\pi \cdot\left(x_{i, t+1}\right)^{m}}{\pi \cdot\left(x_{i, t+1}\right)^{m}+\sum_{j \neq i}\left(x_{j, t+1}\right)^{m}},
$$

and

$$
p_{t+1}^{i, j}=\frac{\left(x_{i, t+1}\right)^{m}}{\pi \cdot\left(x_{j, t+1}\right)^{m}+\left(x_{i, t+1}\right)^{m}+\sum_{l \neq i, j}\left(x_{l, t+1}\right)^{m}},
$$

provided that $x_{i, t+1}+\sum_{j=1}^{n-1} x_{j, t+1}>0$, for $j=1, \ldots, n-1, l=1, \ldots, n-2$, where $m>0$ and $\pi \geq 1.7$ Our modeling strategy recognizes that the conversion of initial property claims into effective property rights must take place within a given framework of legal property rights and social norms. The technology of conflict that is described by (1) and (2) is a reducedform description of how appropriative competition takes place in such a framework. Several features of this process deserve attention. The parameter $\pi$ indicates the effectiveness of the defense of one's own claims against challenge by others. As discussed below, $\pi$ is a measure of the quality of property rights. The parameter $m$ measures the strength of the diminishing returns to appropriation and, thus, it is a measure of the effectiveness of appropriative activities. The number of competing groups, $n$, provides a measure of sociopolitical fragmentation. The anonymity of appropriative competition implies that, given $\pi, m$ and $n$, all that matters for an agent is the stock of each type of capital that is accumulated by his opponents. Their identity is

\footnotetext{
${ }^{7}$ To complete the specification of the conflict technology it is assumed that an arbitrary distribution $\left\{p_{t+1}^{1, i}, \ldots, p_{t+1}^{n, i}\right\}=\left\{\bar{p}_{1}, \ldots, \bar{p}_{n}\right\}$, with $\sum_{j=1}^{n} \bar{p}_{j}=1$, for $i=1, \ldots, n$, results whenever $x_{i, t+1}+\sum_{j=1}^{n-1} x_{j, t+1}=0$.
} 
otherwise irrelevant. In particular, agents take the behavior of others as given and do not take into account the influence of their current behavior on the future behavior of others, because agents understand that they will never meet the same opponent more than once. In addition, we rule out the possibility of coalition formation. Thus, we abstract from strategic behavior and our analysis focuses on the aggregate implications of the externality that is associated with appropriative competition.

Thus, given the current stocks of productive capital $\left\{k_{1, t}, \ldots, k_{i, t}, \ldots, k_{n, t}\right\}$ and the current stocks of appropriative capital $\left\{x_{1, t}, \ldots, x_{i, t}, \ldots, x_{n, t}\right\}$ at date $t$, agent $i$ enjoys effective property rights over

$$
p_{t}^{i, i} A k_{i, t}+\sum_{j \neq i} p_{t}^{i, j} A k_{j, t}
$$

units of output. He then chooses how to allocate these resources across consumption $c_{i, t}$, and investment activities, which in turn determine next-period stocks of productive capital $k_{i, t+1}$ and appropriative capital $x_{i, t+1}$. We allow for the stocks of productive and appropriative capital to depreciate at the constant rates $\delta_{p} \in[0,1]$ and $\delta_{a} \in[0,1]$, respectively. For simplicity, it is assumed that the agents retain control of their current stocks of capital. Accordingly, agent $i$ 's productive investment at date $t$ is given by $k_{i, t+1}-\left(1-\delta_{p}\right) k_{i, t}$, and similarly his appropriative investment is given by $x_{i, t+1}-\left(1-\delta_{a}\right) x_{i, t}$. Thus, at every date $t \geq 0$ agent $i$ faces the resources constraint

$$
p_{t}^{i, i} A k_{i, t}+\sum_{j \neq i} p_{t}^{i, j} A k_{j, t}=c_{i, t}+k_{i, t+1}-\left(1-\delta_{p}\right) k_{i, t}+x_{i, t+1}-\left(1-\delta_{a}\right) x_{i, t}
$$

where, at the initial date $t=0$, every agent is endowed with a stock of productive capital $k_{0}>0$ and a stock of appropriative capital $x_{0}>0$. We will use the fraction of aggregate resources that are allocated into appropriative investment as a measure of the intensity of conflict.

Each agent's objective is to maximize the expected discounted sum of utilities from his consumption stream, taking the behavior of others as given, and all agents discount future 
consumption at the common discount factor $\beta \in(0,1)$. Agent $i$ 's utility in a given period is given by $u\left(c_{i, t}\right)=\log \left(c_{i, t}\right)$.

\subsection{Appropriative Conflict: Interpretation}

Because the technology of conflict is an abstract modeling device to summarize the influence of appropriative competition on the security of property, it is useful to draw a connection between the parameters of the model and the real world.

Cross-country studies increasingly emphasize the empirical relationship between indicators of institutional quality and economic growth. Although ideal measures of institutional quality associated with property rights are not available, the International Country Risk Guide and Business Environmental Risk Intelligence provide indicators of "risk of expropriation", "contract enforceability", "rule of law", and "bureaucratic quality" that are found to be strongly correlated with output growth. These indicators were first used by Keefer and Knack (1997) as proxies for the security of property, although the precise link with institutional quality is missing.

In the present context, $\pi \geq 1$ captures the notion of institutional quality associated with property rights. We see it as depending on the quality of the legal system of property rights as well as the set of social norms that influence the creation of effective property rights. In the limit as $\pi$ approaches infinity each individual's private returns to productive activities become perfectly secure at a negligible cost. Intermediate values of $\pi \in(1, \infty)$ provide a measure of the distance from the perfect system of property rights. At the other extreme, the common-access specification of the conflict technology, which is most often used in the literature, obtains when $\pi=1$, in which case $p_{t+1}^{i, i}$ coincides with agent $i$ 's share of the total available output. 8

\footnotetext{
${ }^{8}$ Most often conflict is modeled by appropriation from a common pool of resources (e.g., Skaperdas (1992) and Hirshleifer (1995)). Grossman and Kim (1995) offer an alternative to this approach, which emphasizes the distinction between predation and defense from predation. Our specification is closest in spirit to theirs. However, they assume that defensive and offensive activities are rival uses of resources and focus on the possibility of an equilibrium which involves no offensive activities. Grossman (2001) suggests that it is the absence or the presence of individual initial claims over resources that distinguishes the two approaches. However, the generalization that is proposed here and the analysis that follows indicate that whether or not individuals are endowed with initial claims makes no essential difference when $\pi=1$. Thus, the model of conflict by appropriation from a common pool can be understood as the special case where $\pi=1$ within the general case where $\pi \geq 1$. We thank Hugh Neary for first suggesting this possibility.
} 
We do not model groups of individuals as organized bodies which engage in strategic competition, and we do not provide a theory of sociopolitical divisions. Instead, our assumption of the random matching of $n$ individuals at every point in time is a simple way to consider the consequences of appropriative competition in the context of impersonal economic interaction. We interpret $n \geq 2$ as a crude measure of sociopolitical fragmentation that influences the potential for conflict and that is distinct from $\pi$. The interpretation of $n$ as the number of competing groups is motivated by the idea that appropriative competition is associated with the distribution of political power, broadly defined, and with the control of different spheres of economic activity by different groups, which are defined by occupation, industry, geography, ethnic identity, and other characteristics. This view is motivated by the increasing evidence of the empirical relationship between measures of sociopolitical fragmentation, institutions and growth. For example, Easterly and Levine (1997), and more recently Alesina et al. (2002), document the negative empirical correlation between measures of linguistic and racial diversity and growth performance across countries. In turn, these measures are highly correlated with indicators of discrimination against minorities, political risk and infrastructure. Mauro (1995) documents the high correlation between measures of ethnic diversity and corruption. These studies suggest that sociopolitical fragmentation has a negative influence on economic growth and that high quality institutions are most necessary when there is a higher degree of fragmentation.

Much conflict is likely to be non-violent and a potentially large cost takes the form of resources allocated to the enforcement of property and contractual rights. ${ }^{9}$ We think of this cost as being associated with appropriative competition and it is the cost which is explicitly emphasized in our model. Interesting case studies that suggest the substantial economic costs that are involved in securing effective property rights include De Soto (1989) and Frye and Shleifer (1997). Barro (1991) documents the negative empirical correlation between political instability and growth. However, identification of the causal mechanism that underlies this correlation is a difficult task, as reflected in the strong empirical correlation between measures of political instability and standard measures of the quality of property rights and the security of property. From the

\footnotetext{
${ }^{9}$ Our model focuses on the economic cost of conflict without explaining how conflict does precisely take place. Brito and Intriligator (1985) emphasize the role of incomplete information for understanding whether or not conflict is resolved with violence.
} 
perspective of the present model, we view political instability as an indirect measure of conflict, which is influenced by the quality of property rights, $\pi$, and by the degree of sociopolitical fragmentation $n$, among other factors.

Two other parameters of the model should be mentioned here. $m$ describes the strength of the diminishing returns to appropriation. It influences the potential for generating more or less intense conflict and is therefore an important aspect of the institutional environment. $\delta_{a}$ reflects how durable appropriative capital is. It may be interpreted as capturing an important aspect of political and social instability. To the extent that redistributive activities often take place within social and political networks, instability is naturally associated with higher values of $\delta_{a}$.

\section{Equilibrium}

Our goal is to understand some of the aggregate implications of the externality that is associated with appropriative conflict as a function of the quality of property rights. We deliberately abstract from asymmetric appropriative competition and from strategic behavior among individuals and groups of individuals. This motivates our focus on the interior symmetric Markov perfect equilibrium under anonymous appropriative competition.

Formally, a Markov strategy of individual $i$ consists of a consumption policy and two in-

vestment policies $\left\{C_{i, t}\left(\psi_{i, t}\right), I_{i, t}^{k}\left(\psi_{i, t}\right), I_{i, t}^{x}\left(\psi_{i, t}\right)\right\}_{t=s}^{\infty}$ that specify $c_{i, t}, k_{i, t+1}-\left(1-\delta_{p}\right) k_{i, t}$ and $x_{i, t+1}-\left(1-\delta_{a}\right) x_{i, t}$, respectively, for $t \geq s$, as functions of the payoff-relevant state variables $\psi_{i, t} \equiv\left\{k_{i, t}, x_{i, t},\left\{k_{j, t}, x_{j, t}\right\}_{j=1}^{n-1}, F_{-i}\left(k_{t}, x_{t}\right)\right\}$, where $\left\{k_{i, t}, x_{i, t}\right\}$ are the current capital stocks of agent $i,\left\{k_{j, t}, x_{j, t}\right\}_{j=1}^{n-1}$ are the capital stocks of agent $i$ 's opponents in the previous period, and $F_{-i}\left(k_{t}, x_{t}\right)=F_{l}\left(k_{t}, x_{t}\right)$, for $l=1, \ldots, n-1$, is the distribution of the capital stocks in each one of the other $n-1$ groups from which agent $i$ 's opponents will be randomly drawn next period. Together with $\left\{k_{i, t}, x_{i, t}\right\},\left\{k_{j, t}, x_{j, t}\right\}_{j=1}^{n-1}$ determine the resources over which agent $i$ enjoys effective property rights at the beginning of period $t$. In forming beliefs about the stock of capital of his opponents next period, agent $i$ uses $F_{-i}$. In a symmetric equilibrium, the (endogenous) distributions $F_{l}$ are degenerate because the actual stock of each type of capital is the same for all agents and, therefore, the actual capital stocks of agent $i$ 's opponents next period are common 
knowledge at date $t$, for all $i$. Thus, $\left\{C_{t}^{\star}\left(\psi_{i, t}\right), I_{t}^{k^{\star}}\left(\psi_{i, t}\right), I_{t}^{x^{\star}}\left(\psi_{i, t}\right)\right\}_{t=s}^{\infty}$, for all $i$, characterizes a symmetric Markov perfect equilibrium if, for all $i, s$,

$$
\begin{gathered}
J\left(\left\{C_{t}^{\star}\left(\psi_{i, t}\right), I_{t}^{k^{\star}}\left(\psi_{i, t}\right), I_{t}^{x^{\star}}\left(\psi_{i, t}\right) ; C_{t}^{\star}\left(\psi_{-i, t}\right), I_{t}^{k^{\star}}\left(\psi_{-i, t}\right), I_{t}^{x^{\star}}\left(\psi_{-i, t}\right)\right\}_{t=s}^{\infty}\right) \\
\quad \geq J\left(\left\{C_{t}\left(\psi_{i, t}\right), I_{t}^{k}\left(\psi_{i, t}\right), I_{t}^{x}\left(\psi_{i, t}\right) ; C_{t}^{\star}\left(\psi_{-i, t}\right), I_{t}^{k^{\star}}\left(\psi_{-i, t}\right), I_{t}^{x^{\star}}\left(\psi_{-i, t}\right)\right\}_{t=s}^{\infty}\right),
\end{gathered}
$$

where $J(\cdot)$ is the value of $\sum_{t=s}^{\infty} \beta^{t-s} \log \left(c_{i, t}\right)$, given the strategies of all agents.

The anonymity of appropriative competition implies that the future behavior of agent $i$ 's current opponents is not payoff-relevant for agent $i$, because agent $i$ understands that he will never meet the same opponent more than once. Thus, even though each agent understands that his claims to property will be challenged by $n-1$ other agents every period, and that his own appropriative activities will effectively challenge the claims of $n-1$ other agents, each agent is small in that he does not influence the aggregate distributions $F_{l}$, for all $l$. Thus, the problem of an agent becomes rather simple. In effect, individual $i$ solves the following problem in every period $t$ : taking as given the strategies of all other agents, choose a plan $\left\{c_{i, t}, k_{i, t+1}, x_{i, t+1}\right\}_{t \geq s}$ that solves

$$
\max \sum_{t=s}^{\infty} \beta^{t-s} \log \left(c_{i, t}\right)
$$

subject to

$$
c_{i, t}=p_{t}^{i, i} A k_{i, t}+\sum_{j \neq i} p_{t}^{i, j} A k_{j, t}-k_{i, t+1}+\left(1-\delta_{p}\right) k_{i, t}-x_{i, t+1}+\left(1-\delta_{a}\right) x_{i, t}
$$

for given initial conditions $k_{i, 0}=k_{0}$ and $x_{i, 0}=x_{0}$, with $c_{i, t}, k_{i, t+1}, x_{i, t+1} \geq 0$ for all $t \geq s$. Because of the anonymity of appropriative competition, agent $i$ 's optimal plan satisfies the pair of Euler equations

$$
\frac{1}{c_{i, t}}=\beta\left(p_{t+1}^{i, i} A+1-\delta_{p}\right) \frac{1}{c_{i, t+1}}
$$




$$
\frac{1}{c_{i, t}}=\beta\left(\frac{\partial p_{t+1}^{i, i}}{\partial x_{i, t+1}} A k_{i, t+1}+\sum_{j \neq i} \frac{\partial p_{t+1}^{i, j}}{\partial x_{i, t+1}} A k_{j, t+1}+1-\delta_{a}\right) \frac{1}{c_{i, t+1}}
$$

for all $t \geq s$ and the transversality conditions

$$
\lim _{t \rightarrow \infty} \beta^{t} \frac{k_{i, t+1}}{c_{i, t}}=0, \quad \text { and } \quad \lim _{t \rightarrow \infty} \beta^{t} \frac{x_{i, t+1}}{c_{i, t}}=0,
$$

together with agent $i$ 's accumulation constraint and the initial conditions. In the Appendix, we use these conditions to construct a plan $\left\{c_{t}, k_{t+1}, x_{t+1}\right\}_{t \geq s}$ that solves problem $(\star)$ for every agent simultaneously (see Theorem 4.15 of Stokey and Lucas (1989)), and to derive the consumption and the investment policies that constitute the interior symmetric Markov perfect equilibrium.

\section{Security of Property and Growth}

When property rights are perfectly secured at a negligible cost to the individuals, that is, when $n=1$ or $\pi=\infty$, individuals enjoy all the returns from their productive activities and the firstbest outcome obtains. Otherwise, the equilibrium is characterized by insecure property. In a symmetric equilibrium, equation (1) implies that the security of individual $i$ 's claims to property is given by

$$
p_{t+1}^{i, i}=\frac{\pi}{\pi+n-1}
$$

for all $i$. Thus, the equilibrium security of property increases with the quality of property rights, $\pi$, and declines with the degree of sociopolitical fragmentation, $n$.

The intertemporal optimality of each individual's behavior, as reflected in (5), then requires that consumption grows at a constant rate according to

$$
c_{t}=c_{0}(1+\gamma)^{t}
$$

where $c_{0}$ is the equilibrium choice of consumption at the arbitrary initial date $s=0$ and 


$$
\gamma \equiv \beta\left(\frac{\pi}{\pi+n-1} A+1-\delta_{p}\right)-1
$$

Consumption growth is, therefore, determined by the individual incentives to engage in productive activities. These are influenced by the need to replace the stock of productive capital which depreciates at the rate $\delta_{p}$, and by the marginal returns to productive investments. In turn, these are driven by the marginal product of capital, $A$, and the security of claims to property, $\pi /(\pi+n-1)$.

We summarize our findings, noting that $c_{t}, k_{t}$, and $x_{t}$, will all grow at the common rate $\gamma$ along the equilibrium path.

Proposition 1 (1) $p_{t+1}^{i, i}$ increases with $\pi$ and declines with $n ;(\mathbf{2}) \gamma$ increases with $\pi, A$ and $\beta$ and it declines with $n$ and $\delta_{p}$.

Thus, increases in the security of property $p_{t+1}^{i, i}$ are always accompanied by increases in the rate of growth $\gamma$.

\section{Conflict and Growth}

Is the intensity of conflict likely to rise or to decline with economic growth? The answer to this question depends on the source of differences in growth and conflict. For example, do societies with better underlying property rights grow faster and suffer less intense appropriative competition than those with lower quality property rights? Do less fragmented societies grow relatively faster and suffer less intense appropriative competition? Or, given the quality of property rights and the degree of sociopolitical fragmentation, are differences in productivity levels associated with a positive or a negative relationship between growth and conflict? These are questions that our model can shed some light on.

For the two Euler equations (5) and (6) to hold simultaneously it must be that the (net) marginal returns to productive and appropriative investments are equal. In turn, this equilibrium balance requires that 


$$
x_{t+1}=\phi k_{t+1}
$$

at all dates $t>0$, where

$$
\phi \equiv\left(\frac{m(n-1) A}{\pi A+(\pi+n-1)\left(\delta_{a}-\delta_{p}\right)}\right)\left(\frac{2 \pi+n-2}{\pi+n-1}\right)
$$

is the equilibrium stock of appropriative capital per unit of the productive capital stock. Higher values of $\phi$ indicate higher returns to appropriation relative to production, which in turn are determined by the conflict and the production technologies. The dependence of $\phi$ on the underlying parameters is recorded in the next proposition.

Proposition $2 \phi$ falls with $\pi$ and with $\left(\delta_{a}-\delta_{p}\right)$; it rises with $m$ and $n$; and it rises with $A$ if and only if $\delta_{a}>\delta_{p}$.

In the Appendix, we show that the interior symmetric equilibrium is given by $I_{t}^{k^{\star}}\left(\psi_{i, t}\right)=$ $i^{k} A k_{t}, I_{t}^{x^{\star}}\left(\psi_{i, t}\right)=i^{x} A k_{t}$ and $C_{t}^{\star}\left(\psi_{i, t}\right)=\left(1-i^{k}-i^{x}\right) A k_{t}$, with the rates of gross investment

$$
\begin{gathered}
i^{k} \equiv \frac{k_{t+1}-\left(1-\delta_{p}\right) k_{t}}{A k_{t}}=\frac{\gamma+\delta_{p}}{A}, \\
i^{x} \equiv \frac{x_{t+1}-\left(1-\delta_{a}\right) x_{t}}{A k_{t}}=\phi\left(\frac{\gamma+\delta_{a}}{A}\right),
\end{gathered}
$$

where $\gamma$ is the equilibrium rate of growth, given by (10), and $\phi$ is the equilibrium stock of appropriative capital per unit of the productive capital, given by (12). ${ }^{10}$ These investment rates also measure the share of the aggregate resources that are allocated into production and appropriation, with $c_{t} /\left(A k_{t}\right)+i^{k}+i^{x}=1$. We use the rate of appropriative investment $i^{x}$ as a measure of the intensity of conflict. In the next section we will discuss the relationship between $i^{x}$ and social welfare. Before then, we will examine the determinants of the intensity of conflict in turn.

\footnotetext{
${ }^{10}$ Necessary conditions for an interior symmetric equilibrium are (1) $\gamma>-\delta_{p},(\mathbf{2}) \phi>0$ and $\gamma>-\delta_{a}$ and (3) $A-\delta_{p}-\delta_{a} \phi-(1+\phi) \gamma>0$, so that $i^{k}>0, i^{x}>0$ and $i^{k}+i^{x}<1$, respectively, where $\gamma$ and $\phi$ are given by (10) and (12) as a function of the parameters.
} 


\subsection{Quality of Property Rights}

From equation (14),

$$
\frac{\partial i^{x}}{\partial \pi}=\frac{1}{A}\left(\left(\gamma+\delta_{a}\right) \frac{\partial \phi}{\partial \pi}+\phi \frac{\partial \gamma}{\partial \pi}\right)
$$

and we see that an increase in $\pi$ induces opposing effects on appropriative conflict. First, $\partial \phi / \partial \pi<0$ reflects how a marginal increase in $\pi$ induces an increase in the returns to production relative to appropriation. Everything else equal, this effect reduces the intensity of conflict. Second, an increase in $\pi$ induces an increase in the security of property, that is, an increase in $p_{t+1}^{i, i}$. This creates stronger incentives for individuals to allocate resources into production, which in turn promotes growth. This effect is captured by $\partial \gamma / \partial \pi>0$. The important point is that faster growth exacerbates the intensity of conflict by creating stronger incentives to allocate resources into appropriative activities, because there are more resources subject to appropriation in every period. Equation (15), thus, indicates that conflict will be exacerbated by an improvement in the quality of property rights whenever the associated increase in the economy's rate of growth is not accompanied by a sufficiently stronger incentive to allocate resources into production relative to appropriation.

One can verify that, at $\pi=1$, a marginal increase in $\pi$ causes $i^{x}$ to rise; when $\pi$ is sufficiently high, however, a marginal increase in $\pi$ causes $i^{x}$ to fall. In the case where both stocks of capital depreciate at the same rate, we have the following result.

Proposition 3 Let $\delta_{a}=\delta_{p}=\delta$ and $\gamma+\delta>0$. Then, $\partial i^{x} / \partial \pi<0$ if and only if $\pi>\pi^{\star}$, where $\pi^{\star}$ is the solution to

$$
\pi^{\star}+n-1-\frac{n}{2 \pi^{\star}+n-2}-\frac{(n-1) \beta \pi^{\star} A}{\beta \pi^{\star} A-\left(\pi^{\star}+n-1\right)(1-\beta)(1-\delta)}=0 .
$$

If $\delta<1$, then $\pi^{\star}>1, \partial \pi^{\star} / \partial A<0$ and $\partial \pi^{\star} / \partial n>0$.

Thus, when $\delta_{a}=\delta_{p}<1$, the model predicts an inverted U-shaped relationship between the proportion of resources that are allocated into appropriative competition, $i^{x}$, and the quality of 
property rights, $\pi$. Together with Proposition 1, this implies that differences in $\pi$ are associated with a non-monotone relationship between conflict, on the one hand, and the security of property and growth, on the other hand. The intuition is this. Growth that is associated with marginal improvements in the quality of property rights initially exacerbates conflict, because the incentives to engage in appropriative activities that are associated with increased growth overwhelm the incentives to tradeoff production and appropriation. However, when the quality of property rights is sufficiently high, further quality improvements always result in a lower intensity of conflict, because the tradeoff between production and appropriation dominates. Furthermore, Proposition 3 indicates that marginal improvements in the quality of property rights are more likely to generate more intense conflict the lower the level of productivity $A$ and the higher the degree of sociopolitical fragmentation $n$, in the sense that $\partial \pi^{\star} / \partial A<0$ and $\partial \pi^{\star} / \partial n>0 .{ }^{11}$

\subsection{Sociopolitical Fragmentation}

Equation (14) also indicates that changes in $n$ induce opposing effects on the rate of appropriative investment. Treating $n$ as continuous,

$$
\frac{\partial i^{x}}{\partial n}=\frac{1}{A}\left(\left(\gamma+\delta_{a}\right) \frac{\partial \phi}{\partial n}+\phi \frac{\partial \gamma}{\partial n}\right)
$$

An increase in $n$ raises the returns to appropriation relative to production, as reflected by $\partial \phi / \partial n>0$. This increases the intensity of conflict. However, an increase in $n$ makes property less secure and, therefore, lowers growth $(\partial \gamma / \partial n<0)$. In turn, less growth lowers the returns to appropriation and discourages conflict. Equation (16) indicates that higher levels of sociopolitical fragmentation, as measured by higher values of $n$, will induce less conflict whenever its negative effect on growth is sufficiently large. Otherwise, more sociopolitical fragmentation will result in both less growth and more conflict. When $\delta_{a}=\delta_{p}$ we have the following result.

Proposition 4 Let $\delta_{a}=\delta_{p}=\delta<1$ and $\gamma+\delta>0$. Then, $\partial i^{x} / \partial n<0$ if and only if $n \geq n^{\star}$,

\footnotetext{
${ }^{11}$ Some evidence that improvements in the quality of property rights may exacerbate the intensity of conflict is provided by André and Platteau (1998). In an interesting case study of a region in Rwanda during the period 1988-1993, the evidence they provide strongly suggests that rapidly rising land disputes were associated with the increasing individualization of land rights and the development of (illegal) land markets.
} 
where $n^{\star}$ is the solution to

$$
\frac{\pi+n^{\star}-1}{n^{\star}-1}-\frac{\pi-1}{2 \pi+n^{\star}-2}-\frac{\beta \pi A}{\beta \pi A-\left(\pi+n^{\star}-1\right)(1-\beta)(1-\delta)}=0,
$$

where $\partial n^{\star} / \partial A>0, \partial n^{\star} / \partial \pi>0$, and $n^{\star}<2$ whenever $\pi=1$.

Thus, when $\delta_{a}=\delta_{p}<1$ and $\pi=1$, higher degrees of sociopolitical fragmentation always generate less intense conflict. This is because sociopolitical fragmentation weakens the security of property and, thus, discourages growth, which in turn tends to lower the intensity of appropriative competition. The proposition indicates that this is the dominant effect at $\pi=1$. It follows by continuity that this will be the case when the quality of property rights is sufficiently poor. However, provided that $\pi$ is sufficiently high, the model predicts an inverted U-shaped relationship between $i^{x}$ and $n$. The reason is that the tradeoff between production and appropriation tends to dominate initially as $n$ increases. Eventually, however, the negative influence of sociopolitical fragmentation on growth will also result in less intense conflict. Together with Proposition 1, this implies that differences in $n$ may induce a non-monotone relationship between conflict, on the one hand, and the security of property and growth, on the other hand. In any case, it is worth emphasizing that sufficiently large differences in sociopolitical fragmentation are necessarily associated with a positive relationship between growth and conflict. Moreover, as the proposition indicates, this positive relationship tends to be the norm rather than the exception when property rights are of relatively poor quality. We will discuss the corresponding welfare implications below. ${ }^{12}$

\subsection{Further Determinants of Appropriative Competition}

We conclude this section with a brief discussion of the influence of $A, \delta_{a}, m$ and $\beta$ on the intensity of appropriative conflict.

\footnotetext{
${ }^{12}$ In a cross-section of African countries, Bates (1999) finds evidence of a non-monotone relationship between measures of ethnicity and political instability. To the extent that political instability reflects the intensity of appropriative conflict, Bates' work suggests that higher degrees of sociopolitical fragmentation, over some range, may be associated with less intense appropriative competition. Propositions 1 and 4 suggest that the influence of ethnic diversity on conflict can be understood in terms of the relationship between sociopolitical fragmentation, growth and conflict.
} 
Differences in productivity also influence the intensity of conflict both through their influence on growth and, when $\delta_{a} \neq \delta_{p}$, the returns to production relative to appropriation. However, it is easy to verify that

$$
\frac{\partial i^{x}}{\partial A}=\frac{\partial(\phi / A)}{\partial A}\left(\gamma+\delta_{a}\right)+\frac{\phi}{A} \frac{\partial \gamma}{\partial A} \geq 0
$$

with strict inequality whenever $\delta_{a}<1$. Following an increase in $A$, the positive effect of faster growth on the intensity of conflict dominates the negative effect of the relative increase in the opportunity cost of appropriative activities when $\delta_{a}<\delta_{p}$, and it is reinforced when $\delta_{a}>\delta_{p}$. Thus, higher levels of productivity unambiguously generate more intense conflict and, therefore, differences in productivity levels generate a positive relationship between growth and conflict. 13

From equation (14), one can also verify that

$$
\frac{\partial i^{x}}{\partial \delta_{a}}=\frac{1}{A}\left(\left(\gamma+\delta_{a}\right) \frac{\partial \phi}{\partial \delta_{a}}+\phi\right)>0
$$

which indicates that less durable appropriative capital, as measured by a higher depreciation rate $\delta_{a}$, is associated with more intense conflict. There are two opposing effects of an increase in $\delta_{a}$. Intuitively, as appropriative capital depreciates faster, it is relatively more profitable to engage in productive investment and so $\phi$ falls. On the other hand, higher investment rates are necessary to sustain a given stock of appropriative capital. It is the latter effect that dominates. One may interpret higher values of $\delta_{a}$ as being associated with higher levels of political instability, in the sense that the stock of appropriative capital loses effectiveness more rapidly when political power shifts relatively more frequently. Under this interpretation, the influence of $\delta_{a}$ on the rate of appropriative investment seems intuitive: an effect of higher instability is that it requires more intense appropriative competition to sustain balanced growth.

\footnotetext{
${ }^{13}$ Gallagher (1991) documents the more than proportionate rise in rents with increases in income, for a sample of African countries from 1975 to 1987 . Tornell and Lane (1999) highlight the positive link between terms of trade improvements and the intensity of public rent-seeking for some countries that appear to have weak institutions and high fragmentation. As an illustration of the extent to which sociopolitical conflict may be exacerbated by productivity increases, Homer-Dixon (1994) traces the ethnic violence that erupted in Senegal and Mauritania in 1989 to plans for the construction of a dam on the Senegal river.
} 
The positive effect of $m$ on the rate of appropriative investment is also intuitive; higher values of $m$ raise the marginal returns to appropriative activities and, thus, encourage appropriative competition. However, whereas higher values of $m$ or $\delta_{a}$ induce more intense conflict, a feature of the equilibrium is that the equilibrium path of the stock of productive capital $\left\{k_{t+1}\right\}_{t \geq 0}$ is independent of $m$ and $\delta_{a}$. Thus, the extent of productive activities is the same for any value of $m>0$ and $\delta_{a} \in[0,1]$, as equation (13) immediately reveals. ${ }^{14}$ The intuition behind this result is that changes in $m$ or $\delta_{a}$ influence the incentives to defend one's own claims to property and challenge those of others symmetrically and, thus, they do not affect the equilibrium distribution of resources, leaving the incentives to engage in productive activities unchanged. ${ }^{15}$ Furthermore, as $m$ becomes negligible the rate of appropriative investment also vanishes, whereas the rate of growth remains inefficiently low. An implication of this is that the extent of the production inefficiency that is associated with insecure property is a function of $n$ and $\pi$, but not $m$.

Finally, it is interesting to note that the intensity of conflict is always higher in an economy in which individuals are more patient, that is, when $\beta$ is higher, as this causes faster growth without influencing the relative return to production and appropriation. ${ }^{16}$ In this sense, cultural stereotypes that suggest that conflict is a problem for those who do not adequately take account of the future have no support in this model.

\footnotetext{
${ }^{14}$ For simplicity, we have not considered the static allocation of time between leisure, labor and appropriation, although it can be incorporated in the present model. It should be noted that this allocation would introduce a different channel (through the choice of labor supply) for $m$ to influence the marginal returns to productive investments, and therefore to influence the economy's growth rate.

${ }^{15}$ One could have modeled the distinction between the defense of property claims and the challenge to them in terms of $m$. This can be done by requiring the strength of the diminishing returns to appropriation to be, say $m_{d}$, when appropriative capital has a defensive role and, say $m_{o}$, in its offensive role. Alternatively, one could assume that appropriative activities are either defensive or offensive, as in Grossman and Kim (1995), and that the stock of defensive capital and offensive capital depreciate at possibly different rates, say $\delta_{a}^{d}$ versus $\delta_{a}^{o}$. By separating the influence of $\pi$ and $m$, our analysis clearly indicates how the agents' incentive to allocate resources into production depends on the security of their property and how the actual cost of securing effective property rights is also influenced by the strength of the diminishing returns to appropriation.

${ }^{16}$ Skaperdas and Syropoulos (1996) have also argued that more myopic agents may have lower incentives to engage in appropriation. In this respect, our analysis complements theirs by showing how the influence of shortsightedness on appropriative competition works through its effect on consumption-saving choices and on growth.
} 


\section{Conflict, Growth and Welfare}

We now consider the welfare implications associated with the fact that insecure property involves a cost in terms of conflict. Do higher quality property rights translate into higher social welfare? How are differences in the degree of fragmentation across otherwise similar economies related to efficiency? Are higher productivity levels welfare improving in economies in which property rights are of poor quality? Do higher rates of patience translate into higher social welfare? Our model can shed some light on these questions. Anticipating our answer to them, we note that a prominent feature of the equilibrium under study is the potential discrepancy between growth and welfare.

We can write the agents' utility from their consumption stream as

$$
U \equiv \sum_{t=0}^{\infty} \beta^{t} \log \left(c_{t}\right)=\frac{1}{1-\beta}\left(\frac{\beta}{1-\beta} \log (1+\gamma)+\log \left(c_{0}\right)\right)
$$

where $c_{0}=\left(1-i^{k}-i^{x}\right) A k_{0}$. This measure of social welfare includes two main elements. The first term within the brackets represents the positive influence of growth on the agent's utility. The second term represents the level effect of consumption on utility. Thus, the allocation of resources into appropriative investments may influence welfare by channeling resources away from productive investments and, therefore, harming growth, and by channeling resources away from consumption.

Proposition $5 \partial U / \partial m<0$ and $\partial U / \partial \delta_{a}<0$.

Since $m$ and $\delta_{a}$ provide an incentive to allocate resources into appropriative competition, and since, as explained above, they do not affect accumulation of productive capital, increases in appropriation that are associated with higher $m$ or higher $\delta_{a}$ take place directly at the expense of consumption and, thus, lower social welfare. Together with the fact that production in the economy is independent of $m$ and $\delta_{a}$, this proposition implies that economic growth may be an extremely poor indicator of welfare and illustrates the idea that growth is not all that matters.

With respect to the influence of higher quality property rights, the following proposition 
provides sufficient conditions for an improvement in the quality of property rights to lower welfare.

Proposition $6 \exists \pi^{\star}>1$ and $\exists m^{\star}>0$ such that, for $\pi \in\left[1, \pi^{\star}\right), \partial U / \partial \pi>0$ if and only if $m<m^{\star}$.

This proposition indicates that, if the quality of property rights under the status quo is sufficiently poor, and if appropriative activities are subject to sufficiently weak diminishing returns, then a marginal improvement in the quality of property rights will result in lower social welfare. The intuition for this result is as follows. When $\pi$ is sufficiently close to $\pi=1$, a small increase in $\pi$ generates both faster growth, that is, higher $\gamma$, and more intense conflict, that is, higher $i^{x}$. Then, whenever appropriation is a sufficiently attractive activity the misallocation of resources away from consumption more than dissipates the benefits from the increased growth associated with improved property rights. This result is driven by the fact that an improvement in the quality of property rights causes resources to be allocated into appropriative activities, away from consumption. In particular, even though productive investment also draws resources away from consumption, this is not the source of welfare losses. This can be seen in that welfare must increase with an improvement in the quality of property rights whenever $m$ is sufficiently close to $m=0$.

To further illustrate the influence of the quality of property rights on growth and welfare, the four panels in Figure 1 plot the equilibrium rate of appropriative investment, the rate of growth, the marginal propensity to consume and the sum of discounted utilities from consumption, respectively, for a range of values of $\pi$ for which the equilibrium restrictions are satisfied. The first panel shows the inverted U-shape of the rate of appropriative investment for values of $\pi$ in the interval $[2,25]$, for $m=1.16$. The second panel illustrates the increase in the equilibrium growth rate $\gamma$ as $\pi$ rises, say from 5 to 15. Over that range, however, the last panel shows that welfare is declining. It takes a further increase in $\pi$ for welfare to improve relative to its level at $\pi=5$. In this case, welfare declines over a range where the rate of appropriative investment declines as well. Thus, this is a different case from that described in Proposition 6, where welfare losses were associated with increases in $i^{x}$. However, the underlying mechanism is the same. Here, the incentive to allocate resources into appropriation is not declining sufficiently 
rapidly and, thus, the marginal propensity to consume is declining too rapidly as $\pi$ increases, as illustrated in the third panel in the figure.

With respect to the influence of sociopolitical fragmentation on welfare we have the following result.

Proposition $7 \exists \pi^{\star}>1$ and $\exists m^{\star}>0$ such that, for $\pi \in\left[1, \pi^{\star}\right), \partial U / \partial n<0$ if and only if $m<m^{\star}$.

This proposition indicates that, if the quality of property rights is sufficiently poor, and if appropriative activities are sufficiently attractive, then higher degrees of sociopolitical fragmentation will be associated with higher social welfare. This is because a larger number of competing groups generates less intense conflict when the quality of property rights is sufficiently poor. In turn, when appropriative activities are sufficiently attractive, the decline in appropriative investment associated with more sociopolitical fragmentation has a sufficiently large positive effect on utility to more than offset the negative influence of the associated decline in growth. Despite the fact that a larger number of competing groups may be associated with relatively higher welfare, it should be noted that the presence of sociopolitical fragmentation has a negative influence on welfare in this model. In particular, fragmentation can only discourage conflict by depressing growth. Thus, social welfare when $n \geq 2$ is necessarily lower than that associated with $n=1$.

Figure 2 gives some sense of the quantitative relevance of this case. The panels in Figure 2 are as in Figure 1. In this case, they illustrate how higher levels of sociopolitical fragmentation can lead to lower welfare when $n$ is relatively low, but they improve welfare at higher values of $n$ precisely because the economy's rate of growth declines sufficiently fast with $n$. This is shown here for the case where $\pi=15$ and $m=1.2$. As explained above, for lower values of $\pi$ the relationship between $i^{x}$ and $n$ is more likely to be negative and, thus, welfare is more likely to increase with $n$.

Next we look at the relationship between productivity differences and welfare.

Proposition 8 Let $\delta_{a} \geq \delta_{p}$. (1) $\exists m^{\star}>0$ such that, $\partial U / \partial A<0$ if and only if $m>m^{\star}$. (2) If $\delta_{a}=\delta_{p}$, then (2.a) if $m<m^{\star \star}$, then $\partial U / \partial A>0$ for all $A$ and (2.b) if $m>m^{\star \star}$, then $\exists A^{\star}$ 
such that $\partial U / \partial A<0$ if and only if $A>A^{\star}$, where

$$
m^{\star \star}=\left(\frac{\pi+n-1}{\beta(n-1)(2 \pi+n-2)}\right)(n-1+(1-\beta) \pi) .
$$

The first statement in the proposition says that, when the stock of appropriative capital depreciates faster than the stock of productive capital, productivity increases result in lower welfare whenever $m$ is sufficiently high. The second statement in the proposition applies to the case where both stocks of capital depreciate at the same rate. It says that, when $m$ is sufficiently low, higher productivity levels are associated with higher social welfare for any value of $A$; but when $m$ is sufficiently high, productivity increases will eventually harm welfare. Thus, for a given quality of property rights and a given degree of sociopolitical fragmentation, there is a limit to how high productivity levels can be without harming social welfare. This result is due to the fact that higher productivity levels channel resources from consumption to appropriative activities. In particular, we note that the proportion of resources that are allocated into productive investment, $i^{k}$, does not increase with productivity. 17

We conclude by briefly discussing the relationship between individuals' shortsightedness and social welfare. This provides a further illustration of how appropriative competition may greatly influence economic activity and its welfare consequences.

Proposition 9 For any $\beta<1, \exists m^{\star}>0$ such that $\partial U / \partial \beta>0$ if and only if $m<m^{\star}$.

It is clear that productive investment and, thus, economic growth, is favored by the individuals' ability to look ahead. It is also clear that, as $\beta$ approaches 1 , then the positive influence of $\beta$ on growth results in increased social welfare. That is, sufficient farsightedness is also associated with higher social welfare. However, as explained above, higher discount factors are also associated with more intense conflict and, thus, misallocation of resources. Proposition 9 indicates that relatively higher rates of patience are not only conducive to more intense conflict, but are also associated with lower welfare whenever appropriative activities are sufficiently effective.

\footnotetext{
${ }^{17}$ One can see from equation (13) that $\partial i^{k} / \partial A \leq 0$ with strict inequality whenever $\delta_{p}<1$.
} 


\section{Conclusion}

In this paper we have explored a model in which economic growth and the security of property are jointly determined as a function of the quality of the underlying system of property rights, the degree of sociopolitical fragmentation and the economy's level of productivity. We have used the expenditure on appropriative competition as a measure of conflict and we have explored the relationship between conflict and growth. The model accounts for a negative tradeoff between productive and appropriative activities. In equilibrium, however, the intensity of appropriative competition tends to increase with growth, because growth raises the resources that may be subject to appropriation. Thus, a positive relationship between conflict and growth is a natural outcome of the model. This relation is most clearly driven by productivity differences, but it may also be associated with differences in the quality of property rights and the degree of fragmentation. In effect, high levels of sociopolitical fragmentation tend to depress growth to the extent that they also discourage conflict. On the other hand, a negative relationship between growth and conflict is naturally associated with large differences in the quality of property rights. More generally, the model implies an inverted U-shaped relationship between the intensity of conflict and the quality of property rights, and also between the intensity of conflict and the degree of sociopolitical fragmentation.

Perhaps the most interesting implication of the model is that a small improvement in the quality of property rights may actually harm welfare. A sufficiently large institutional improvement, however, is always beneficial. This observation provides an argument in favor of the idea that institutional reform should, in certain cases, take the form of a major institutional change. This is in line with Shleifer's (1997) observation that the apparent failure of Russia's economic transition, as compared with the transition in Poland, can be tracked to Russia's slow political transition. A more general implication of the present analysis is that the adoption of the Western-style economic systems might tend to exacerbate appropriative competition and even reduce welfare unless it is accompanied by sufficient institutional change.

The model also implies that welfare may, everything else equal, be higher in a more fragmented society. On the other hand, sociopolitical fragmentation in the present model is unam- 
biguously harmful, relative to the first best allocation, because relatively less intense conflict in a more fragmented society is only possible, ceteris paribus, at the expense of growth. Thus, our analysis suggests that the observation of low levels of appropriative competition in a stagnant society may reflect the fact that slow growth discourages appropriative competition. A further implication is that there may be a large social benefit associated with institutional improvements even in societies which do not experience intense conflict. Finally, we have shown that higher productivity levels can induce sufficiently large increases in the intensity of appropriative competition that social welfare can be depressed. Overall, the model supports the idea that policies that are aimed at reducing appropriative competition may be particularly desirable, because they lower the cost which is associated with increased growth.

To the extent that the relation between sociopolitical conflict and economic growth is expected to be non-linear and to depend on the quality of property rights, the model indicates why there might be substantial gains from increasing the flexibility of econometric specifications in cross-country growth studies. Along the lines of North (1987), the present analysis also raises questions about the measurement of the efficiency of political and economic institutions. For instance, implicitly our analysis motivates the need to devote further effort to distinguishing between productive and unproductive investments in the context of national income accounting. 


\section{A Appendix}

\section{Equilibrium}

In a symmetric equilibrium, $p_{t+1}^{i, i}$ is given by equation (8), $\gamma$ is given by (10) and the path of consumption for individual $i$ is characterized by equation (9) as a function of $\gamma$ and $c_{0}$. It remains to determine $c_{0}$. Noting that $p_{t+1}^{i, i}+\sum_{j \neq i} p_{t+1}^{i, j}=1$ in a symmetric equilibrium, and that $x_{t+1}=\phi k_{t+1}$, as given by equations (11) and (12), each agent's resources constraint can be written as

$$
\left(A+\left(1-\delta_{p}\right)+\phi\left(1-\delta_{a}\right)\right) k_{t}=c_{0}(1+\gamma)^{t}+(1+\phi) k_{t+1}
$$

where we have used the fact that $x_{0}=\phi k_{0}$. The solution to this difference equation, consistent with the transversality conditions given in (7) and with $c_{0}>0$, is given by

$$
k_{t}=\frac{(1+\gamma)^{t} c_{0}}{A+\left(1-\delta_{p}\right)+\left(1-\delta_{a}\right) \phi-(1+\phi)(1+\gamma)}
$$

It follows that the policies $C_{t}^{\star}\left(\psi_{i, t}\right)=\left(1-i^{k}-i^{x}\right) A k_{t}, I_{t}^{k^{\star}}\left(\psi_{i, t}\right)=i^{k} A k_{t}$ and $I_{t}^{x^{\star}}\left(\psi_{i, t}\right)=$ $i^{x} A k_{t}$ with $i^{k}$ and $i^{x}$ given by (13) and (14) respectively, solve agent $i$ 's problem ( $\star$ ) given that all other agents also follow these policies and they therefore constitute an equilibrium, provided that (1) $\gamma>-\delta_{p}$, (2) $\phi>0$ and $\gamma>-\delta_{a}$ and (3) $A-\delta_{p}-\delta_{a} \phi-(1+\phi) \gamma>0$, so that $k_{t+1}, x_{t+1}, c_{t}>0$ for all $t \geq 0$, and that the agents' utility from their consumption stream is bounded. That this latter condition holds when $\beta<1$ can be seen directly in equation (19).

\section{Proof of Proposition 1}

It follows from (8) and (10).

\section{Proof of Proposition 2}

It follows from (12). 


\section{Proof of Proposition 3}

Let $\delta_{a}=\delta_{p}=\delta$. Differentiating equation (14), $\partial i^{x} / \partial \pi \geq 0$ if and only if

$$
\pi+n-1-\frac{n}{2 \pi+n-2} \leq \frac{(n-1) \beta \pi A}{\beta \pi A-(\pi+n-1)(1-\beta)(1-\delta)},
$$

where the right side of the inequality is positive, provided that $\gamma+\delta>0$. The left side of (22) is increasing with $\pi$ and the right side is declining with $\pi$. At $\pi=1,(22)$ holds with strict equality whenever $\delta<1$. In the limit as $\pi$ approaches $\infty(22)$ never holds true. Hence, there is a unique $\pi^{\star}>1$ such that (22) is satisfied if and only if $\pi<\pi^{\star}$, where $\pi^{\star}$ is the value of $\pi$ that solves (22) with equality. Straightforward differentiation shows that $\partial \pi^{\star} / \partial A<0$ and $\partial \pi^{\star} / \partial n>0$ whenever $\delta<1$. This concludes the proof.

\section{Proof of Proposition 4}

Let $\delta_{a}=\delta_{p}=\delta<1$. Differentiating equation (14), $\partial i^{x} / \partial n \leq 0$ if and only if

$$
\frac{\pi+n-1}{n-1}-\frac{\pi-1}{2 \pi+n-2} \leq \frac{\beta \pi A}{\beta \pi A-(\pi+n-1)(1-\beta)(1-\delta)}
$$

where the right side of the inequality is positive, provided that $\gamma+\delta>0$. The left side of (23)

is decreasing with $n$ and the right side is increasing with $n$. As $n$ increases, $\gamma+\delta$ approaches zero, and the right side of (23) approaches $\infty$, provided that $\delta<1$, Thus (23) must hold with strict inequality. As $n$ approaches 1, (23) never holds. Hence, there is a unique $n^{\star}>1$ such that (23) holds if and only if $n>n^{\star}$, where $n^{\star}$ is the value of $n$ that solves (23) with equality. Since $\gamma+\delta>0, n^{\star}<2$ when $\pi=1$. Straightforward differentiation shows that $\partial n^{\star} / \partial A>0$, $\partial n^{\star} / \partial \pi>0$. This concludes the proof.

\section{Proof of Proposition 5}

It follows from equation (19).

\section{Proof of Proposition 6}

Differentiating equation (19),

$$
\frac{\partial U}{\partial \pi}=\frac{1}{1-\beta}\left(\frac{\beta}{1-\beta} \frac{1}{1+\gamma} \frac{\partial \gamma}{\partial \pi}+\frac{1}{c_{0}} \frac{\partial c_{0}}{\partial \pi}\right),
$$


where

$$
\frac{\partial c_{0}}{\partial \pi}=-k_{0}\left(\frac{\partial \gamma}{\partial \pi}+\phi \frac{\partial \gamma}{\partial \pi}+\left(\gamma+\delta_{a}\right) \frac{\partial \phi}{\partial \pi}\right)
$$

From (15), it is easy to verify that $\partial i^{x} / \partial \pi>0$ at $\pi=1$. By continuity, there exists a number $\pi^{\star}>1$ such that this inequality holds for $\pi \in\left[1, \pi^{\star}\right)$. Now, note that $\partial i^{x} / \partial \pi>0$ implies that $\partial c_{0} / \partial \pi<0$, for all $m \geq 0$. Since $\partial \phi / \partial m>0$ and it approaches zero as $m \rightarrow 0$ and it approaches $\infty$ as $m \rightarrow \infty$, then $\partial c_{0} / \partial m<0$ and there exists a number $\bar{m}>0$ such that $c_{0}>0$ if and only if $m<\bar{m}$. Next, note that $\partial U / \partial \pi$ is decreasing with $m$, that $\partial U / \partial \pi>0$ in the limit as $m \rightarrow 0$, and that $\partial U / \partial \pi<0$ in the limit as $m \rightarrow \bar{m}$. By continuity, there exists a number $m^{\star} \in(0, \bar{m})$ such that $c_{0}>0$ and $\partial U / \partial \pi=0$. This concludes the proof.

\section{Proof of Proposition 7}

Differentiating equation (19),

$$
\frac{\partial U}{\partial n}=\frac{1}{1-\beta}\left(\frac{\beta}{1-\beta} \frac{1}{1+\gamma} \frac{\partial \gamma}{\partial n}+\frac{1}{c_{0}} \frac{\partial c_{0}}{\partial n}\right),
$$

where

$$
\frac{\partial c_{0}}{\partial n}=-k_{0}\left(\frac{\partial \gamma}{\partial n}+\phi \frac{\partial \gamma}{\partial n}+\left(\gamma+\delta_{a}\right) \frac{\partial \phi}{\partial n}\right)
$$

From (16), it is easy to verify that $\partial i^{x} / \partial n<0$ at $\pi=1$. By continuity, there exists a number $\pi^{\star}>1$ such that this inequality holds for $\pi \in\left[1, \pi^{\star}\right)$. Now note that $\partial i^{x} / \partial n<0$ implies that $\partial c_{0} / \partial n>0$, for all $m \geq 0$. Since $\partial \phi / \partial m>0$ and it approaches zero as $m \rightarrow 0$ and it approaches $\infty$ as $m \rightarrow \infty$, then $\partial c_{0} / \partial m<0$ and there exists a number $\bar{m}>0$ such that $c_{0}>0$ if and only if $m<\bar{m}$. Next, note that $\partial U / \partial n$ is increasing with $m$, that $\partial U / \partial n<0$ in the limit as $m \rightarrow 0$, and that $\partial U / \partial n>0$ in the limit as $m \rightarrow \bar{m}$. By continuity, there exists a number $m^{\star} \in(0, \bar{m})$ such that $c_{0}>0$ and $\partial U / \partial n=0$. This concludes the proof.

\section{Proof of Proposition 8}

Differentiating equation (19),

$$
\frac{\partial U}{\partial A}=\frac{1}{1-\beta}\left(\frac{\beta}{1-\beta} \frac{1}{1+\gamma} \frac{\partial \gamma}{\partial A}+\frac{1}{c_{0}} \frac{\partial c_{0}}{\partial A}\right)
$$


where

$$
\frac{\partial c_{0}}{\partial A}=k_{0}\left(1-\frac{\partial \gamma}{\partial A}-\phi \frac{\partial \gamma}{\partial A}-\left(\gamma+\delta_{a}\right) \frac{\partial \phi}{\partial A}\right)
$$

To prove (1), note that $\partial c_{0} / \partial A<0$ if and only if

$$
\left(\gamma+\delta_{a}\right) \frac{\partial \phi}{\partial A}>1-(1+\phi) \frac{\partial \gamma}{\partial A}
$$

or, equivalently, if and only if

$$
\phi>\frac{1-\beta \frac{\pi}{\pi+n-1}}{\beta \frac{\pi}{\pi+n-1}+\left(\gamma+\delta_{a}\right)\left(\frac{1}{A}-\frac{\pi}{\pi A+(\pi+n-1)\left(\delta_{a}-\delta_{p}\right)}\right)} .
$$

Since $\partial \phi / \partial m>0$ and it approaches zero as $m \rightarrow 0$ and it approaches $\infty$ as $m \rightarrow \infty$, then there exists a number $\bar{\phi}>0$ (associated with a number $\bar{m}>0$ ) such that $\partial c_{0} / \partial A<0$ if and only if $\phi>\bar{\phi}$, where $\bar{\phi}$ is given by the right side of (31). Furthermore, $c_{0}>0$ requires that

$$
\phi<\frac{A-\gamma-\delta_{p}}{\gamma+\delta_{a}}
$$

When $\delta_{a} \geq \delta_{p}$, the right side of (32) is decreasing in $A$ while the right side of (31) is increasing in $A$. In addition, the right sides of (31) and (32) become equal as $A$ approaches $\infty$. Thus, for $A<\infty$

$$
\bar{\phi}<\frac{A-\gamma-\delta_{p}}{\gamma+\delta_{a}}
$$

Hence, there exists a number $m$ such that both (31) and (32) hold true, so that $c_{0}>0$ and $\partial c_{0} / \partial A<0$. Since $\left(1 / c_{0}\right)\left(\partial c_{0} / \partial A\right)$ is decreasing with $m$ whenever $\partial c_{0} / \partial A<0$, and since $c_{0} \rightarrow 0$ as $\phi$ approaches $\left(A-\gamma-\delta_{p}\right) /\left(\gamma+\delta_{a}\right)$, it follows that there exists a number $m^{\star}>0$ such that $\partial U / \partial A=0$, consistent with $c_{0}>0$. This proves (1).

To show (2), suppose that $\delta_{a}=\delta_{p}=\delta$. In this case, $\partial c_{0} / \partial A<0$ if and only if

$$
\frac{\partial \gamma}{\partial A}>\frac{1}{1+\phi}
$$

Using the definitions of $\gamma$ and $\phi$, it follows immediately that $\partial c_{0} / \partial A<0$ if and only if $m>m^{\star \star}$, where $m^{\star \star}$ is given by Proposition 8 in the main text. (2.a) follows since $\partial U / \partial A>0$ if $\partial c_{0} / \partial A>0$. 
To show (2.b), let $\delta_{a}=\delta_{p}=\delta$ and let $m>m^{\star \star}$. Then $\partial c_{0} / \partial A<0$. Since $\delta_{a}=\delta_{p}$, $\partial \phi / \partial A=0$ and $\left(1 / c_{0}\right)\left(\partial c_{0} / \partial A\right)$ is decreasing in $A$, approaching $-\infty$ as $c_{0} \rightarrow 0$. Since $\partial \gamma / \partial A$ is not a function of $A$, it follows from equation (28) that there exists a number $A^{\star}$ such that $\partial U / \partial A \leq 0$ if and only if $\mathrm{A} \geq A^{\star}$. This concludes the proof.

\section{Proof of Proposition 9}

Differentiating equation (19),

$$
\begin{aligned}
\frac{\partial U}{\partial \beta} & =\frac{1}{(1-\beta)^{2}}\left(\frac{\beta}{1-\beta} \log (1+\gamma)+\log \left(c_{0}\right)\right) \\
& +\frac{1}{1-\beta}\left(\frac{1}{1-\beta} \log (1+\gamma)+\frac{1}{1-\beta}+\frac{1}{c_{0}} \frac{\partial c_{0}}{\partial \beta}\right),
\end{aligned}
$$

where

$$
\frac{\partial c_{0}}{\partial \beta}=-(1+\phi) \frac{\partial \gamma}{\partial \beta}
$$

Since $\partial \phi / \partial m>0$ and it approaches zero as $m \rightarrow 0$ and it approaches $\infty$ as $m \rightarrow \infty$, then $\partial c_{0} / \partial m<0$ and there exists a number $\bar{m}>0$ such that $c_{0}>0$ if and only if $m<\bar{m}$. The proposition follows by noting that $\partial U / \partial \beta$ is declining with $m$, that $\partial U / \partial \beta>0$ in the limit as $m \rightarrow 0$, and that $\partial U / \partial \beta<0$ in the limit as $m \rightarrow \bar{m}$. 


\section{References}

Alesina, A., A. Devleeschauwer, W. Easterly, S. Kurlat and R. Wacziarg (2002): "Fractionalization." NBER Working Paper 9411.

André, C. and J.P. Platteau (1998): "Land relations under unbearable stress: Rwanda caught in the Malthusian trap." Journal of Economic Behavior and Organization 34(1), 1-47.

Besley, T. (1995): "Property Rights and Investment Incentives: Theory and Evidence from Ghana." Journal of Political Economy 103(5), 903-937.

Bhagwati, J.N. (1982): "Directly Unproductive, Profit-Seeking (DUP) Activities." Journal of Political Economy 90, 988-1002.

Baland, J.M. and P. Francois (2000): “"Rent-seeking and resource booms." Journal of Development Economics 61, 527-542.

Barro, R.J. (1991): "Economic Growth in a Cross-Section of Countries." Quarterly Journal of Economics 106(2), 407-443.

Bates, R.H. (1999): "Ethnicity, Capital Formation, and Conflict." Center for International Development at Harvard University, Working Paper No. 27.

Brito, D.L. and M.D. Intriligator (1985): "Conflict, War, and Redistribution." American Political Science Review 79(4), 943-957.

Baumol, W.J. (1990): "Entrepreneurship: Productive, Unproductive, and Destructive.” Journal of Political Economy 98(5), Part 1, 893-921.

Benhabib, J. and A. Rustichini (1996): "Social Conflict and Growth." Journal of Economic Growth 1(1), 125-142.

De Soto, H. (1989): The Other Path: The Invisible Revolution in the Third World. New york: Harper and Row.

Easterly, W. and R. Levine (1997): "Africa's Growth Tragedy: Policies and Ethnic Divisions." Quarterly Journal of Economics 112(4), 1203-1250. 
Esteban, J. and D. Ray (1999): "Conflict and Distribution." Journal of Economic Theory $87(2), 379-415$.

Frye, T. and A. Shleifer (1997): "The Invisible Hand and the Grabbing Hand." American Economic Review, Papers and Proceedings 87(2), 354-358.

Gallagher, M. (1991): Rent-Seeking and Economic Growth in Africa. Boulder: Westview Press.

Grossman, H.I. (2001): "The Creation of Effective Property Rights." American Economic Review, Papers and Proceedings 91(2), 347-352.

Grossman, H.I. and Minseong Kim (1995): "Swords or Plowshares? A Theory of the Security of Claims to Property." Journal of Political Economy 103, 1275-1288.

Grossman, H.I. and Minseong Kim (1996): "Predation and Accumulation." Journal of Economic Growth 1, 333-350.

Grossman, H.I. and Juan Mendoza (2002): "Scarcity and Appropriative Competition." (Unpublished).

Hall, R.E. and C.I. Jones (1999): "Why Do Some Countries Produce So Much More Output Per Worker Than Others?" Quarterly Journal of Economics, 83-116.

Hirshleifer, J. (1988): "The Analytics of Continuing Conflict." Synthese 76, 201-233.

Hirshleifer, J. (1991a): "The Paradox of Power." Economics and Politics 3, 177-200.

Hirshleifer, J. (1991b): "The Technology of Conflict as an Economic Activity." American Economic Review 81(2), 130-134.

Hirshleifer, J. (1995): “Anarchy and its Breakdown." Journal of Political Economy 103(1), $26-52$.

Homer-Dixon, T.F. (1994): "Environmental Scarcities and Violent Conflict: Evidence from Cases." International Security 19(1), 5-40.

Keefer, P. and S. Knack (1997): "Why Don’t Poor Countries Catch Up? A Cross-National Test of an Institutional Explanation." Economic Inquiry 35, 590-602. 
Khan, M.H. and Jomo, K.S. (2000): Rents, Rent-Seeking and Economic Development: Theory and Evidence in Asia. New York: Cambridge University Press.

Krueger, A.O. (1974): "The Political Economy of the Rent-Seeking Society." American Economic Review 64, 291-303.

Lee, J. and S. Skaperdas (1998): "Workshops or Barracks? Productive Versus Enforcive Investment and Economic Performance." In Advances in Applied Microeconomics, Vol. 7, 103-113. JAI Press Inc..

LLoyd-Ellis, H. and N. Marceau (2002): "Endogenous Insecurity and Economic Development." Journal of Development Economics, forthcoming.

Mauro, P. (1995): "Corruption and growth." Quarterly Journal of Economics 110, 681-712.

Murphy, K.M., A. Shleifer and R.W. Vishny (1991): "The Allocation of Talent: Implications for Growth." Quarterly Journal of Economics 106(2), 503-530.

Murphy, K.M., A. Shleifer and R.W. Vishny (1993): "Why Is Rent-Seeking So Costly to Growth?" American Economic Review, Papers and Proceedings 83, 409-414.

Neary, H.M. (1997): "Equilibrium Structure in an Economic Model of Conflict." Economic Inquiry 35(3), 480-494.

North, D.C. (1987): "Institutions, Transaction Costs and Economic Growth." Economic Inquiry 25, 419-428.

Shleifer, A. (1997): “Government in Transition." European Economic Review 41(3-5), 385-410.

Skaperdas, S. (1992): "Cooperation, Conflict, and Power in the Absence of Property Rights." American Economic Review 82(4), 720-739.

Skaperdas, S. (1996): “Contest success functions." Economic Theory 7, 283-290.

Skaperdas, S. and C. Syropoulos (1996): "Can the shadow of the future harm cooperation?" Journal of Economic Behavior and Organization 29(3), 355-372. 
Stokey, N.L. and R.E. Lucas (1989): Recursive Methods in Economic Dynamics. Cambridge: Harvard University Press.

Sturzenegger, F. and M. Tommasi (1994): "The Distribution of Political Power, the Costs of Rent-Seeking, and Economic Growth.” Economic Inquiry 32, 236-248.

Tornell, A. (1997): "Economic Growth and Decline with Endogenous Property Rights." Journal of Economic Growth 2, 219-250.

Tornell, A. and P.R. Lane (1999): "The Voracity Effect." American Economic Review 89(1), $22-46$.

Tullock, G. (1967): "The Welfare Costs of Tariffs, Monopolies, and Theft." Western Economic Journal 5, 224-232. 
Figure 1: quality of property rights
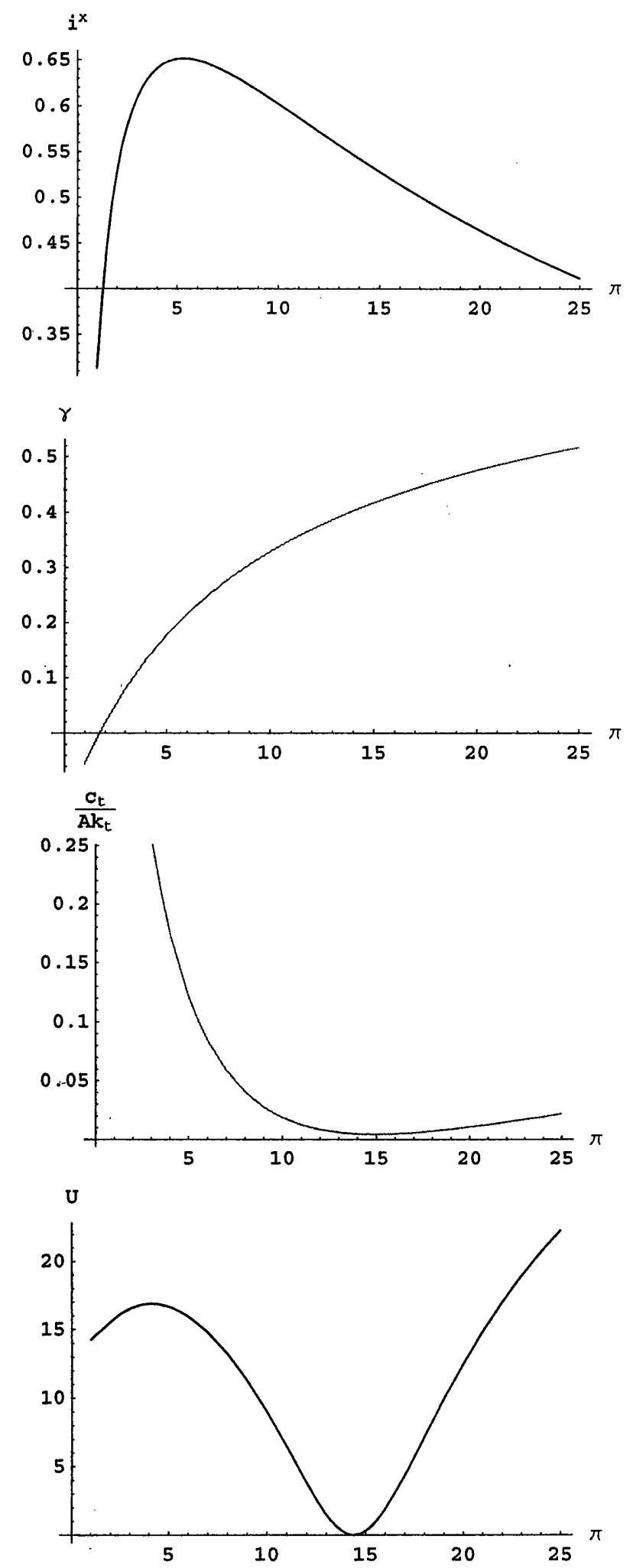

Parameter values: $A=1, \beta=0.9, \delta_{a}=0.1, \delta_{p}=0.05, m=1.16, n=10, k_{0}=10$ 
Figure 2: sociopolitical fragmentation
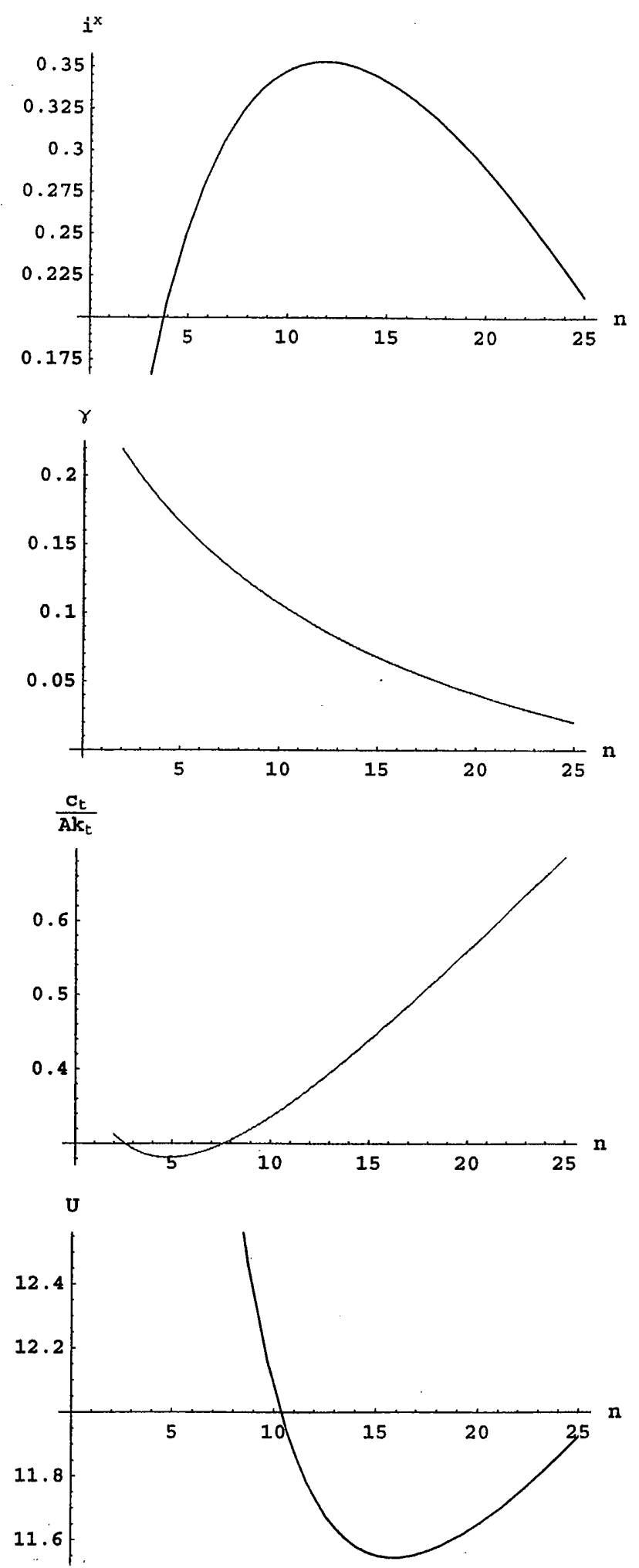

Parameter values: $\pi=15, A=0.4, \beta=0.9, \delta_{a}=0.01, \delta_{p}=0.02, m=1.2, k_{0}=10$ 